\title{
A CASE OF HUMAN INFECTION
}

\section{WITH LEPTOSPIRA MINI GEORGIA}

\author{
A. F. Goley, M.D. \\ A. D. Alexander, M.S. \\ J. F. Thiel, B.A. \\ v. E. Chappell, B.S.
}

Leptospira mini, subserotype georgia, was first isolated from the kidney of a raccoon trapped in Georgia in 1956. This serotype is related to members of the hebdomadis group and has repeatedly been demonstrated in naturally occurring infections in raccoons and opossums. Results of a study of leptospires isolated from these animals are reported on pages $917-$ 921. However, the infectivity of this antigenic type for man or domestic animals has never been established. A case of infection in man with $L$. mini georgia incurred through a laboratory accident is presented.

\section{Case Report}

A 53-year-old white male bacteriologist of the Veterinary Division of Walter Reed Army Institute of Research was apparently well until February 11, 1959, when he accidentally pricked his finger with a needle in the course of injecting rabbits with a culture of $L$. mini georgia. $\mathrm{He}$ immediately expressed blood from the wound and cleansed it with alcohol. He felt well for

Dr. Goley is with the Yale School of Medicine, New Haven, Conn. He was formerly with the Department of Bacteriology, Division of Communicable Diseases, Walter Reed Army Institute of Research, Washington, D.C. Mr. Alexander is with the institute's Department of Veterinary Bacteriology; Mr. Thiel and Mr. Chappell were formerly with that department. Mr. Thiel is now with the Laboratory of Viral Products, National Institutes of Health, Public Health Service, and Mr. Chappell is a student at the University of Illinois, department of animal sciences, Urbana.
25 days, then on the night of March 8, 1959, he had a sudden onset of chilliness, followed by fever and a severe frontal headache. During the next 36 hours he developed generalized muscular aching and mild nausea. He continued to have chills every 2 or 3 hours, and his temperature rose to $103.4^{\circ} \mathrm{F}$.

He was first seen on the second day of illness. At this time he was found to be a welldeveloped, moderately obese man who appeared acutely ill. His temperature was $103^{\circ}$ F., pulse 100, blood pressure 138/85. His chest was clear and there were no palpable nodes. He had no scleral icterus, conjunctival injection, nuchal rigidity, hepatic tenderness, or rash. Laboratory studies were made, and he was given aureomycin, $500 \mathrm{mg}$. orally, every 6 hours. During the next 48 hours his symptoms continued, and his physical findings remained unchanged except for the appearance of mild conjunctival suffusion. On the night of the sixth day of illness his fever dropped by crisis, and his headache and nausea disappeared. His only complaint for the next 10 days was weakness; however, on March 23, he had a recurrence of fever, malaise, and nausea. This subsided after 24 hours and he continued to improve. Convalescence was characterized by weakness but was otherwise uneventful. He returned to work 28 days after the onset of his illness.

At no time during his illness was there hepatic enlargement or tenderness. There was no evidence of meningeal involvement. He had no history of exposure to animals outside of the laboratory, and none of the other members of his family became ill. 


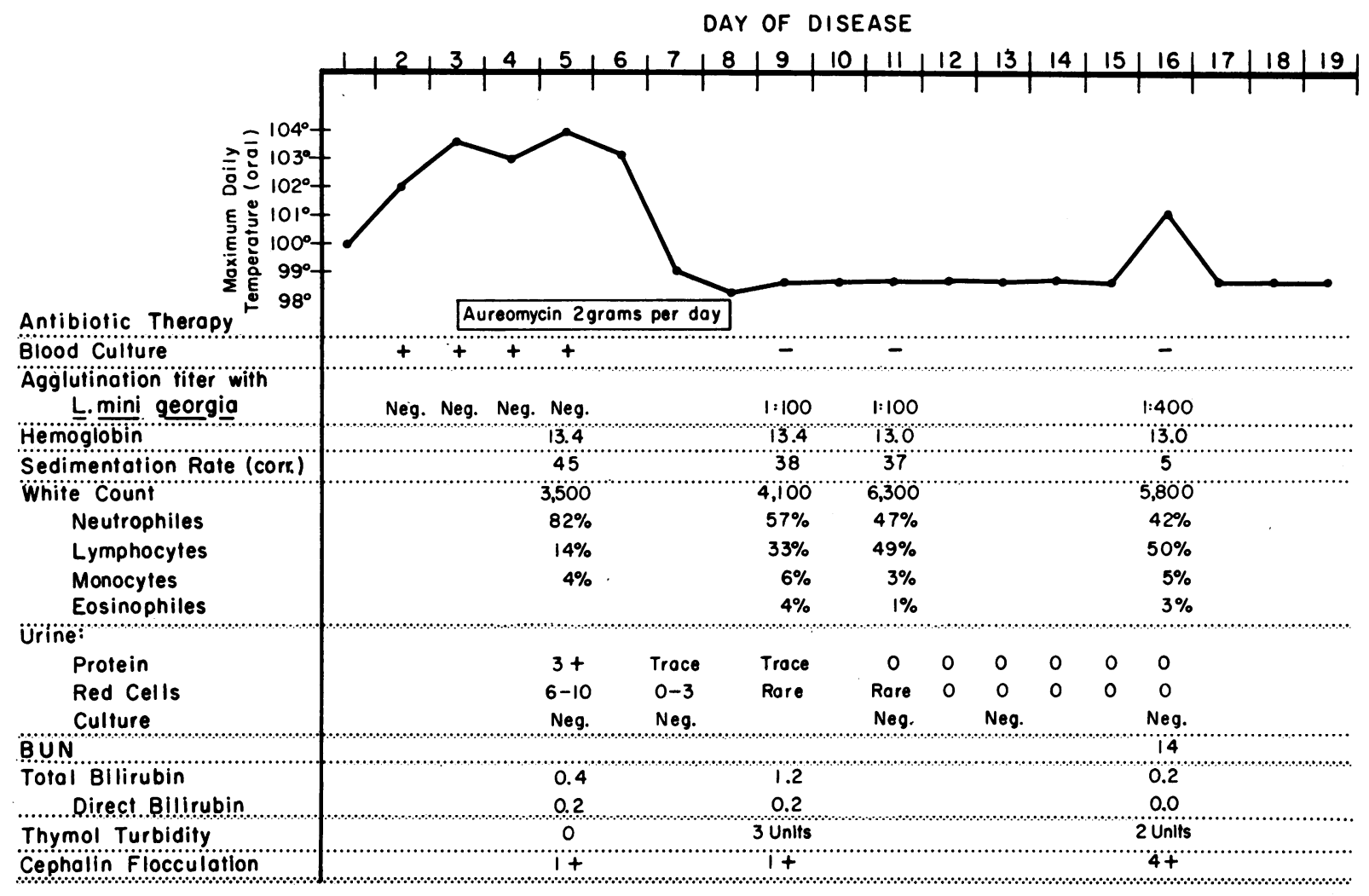

\section{Laboratory Findings}

The temperature curve and laboratory findings are summarized in the accompanying chart. The leucopenia during the acute phase of the disease should be noted. The albuminuria and hematuria might reflect minimal renal involvement; however, repeated urine cultures failed to demonstrate leptospires.

L. mini georgia was recovered by blood culture in Fletcher's medium from the second through the fifth day of disease. This occurred on two occasions in spite of aureomycin blood levels of $1.28 \mu \mathrm{g} . / \mathrm{ml}$. Hamsters and guinea pigs inoculated with the patient's blood developed no evident disease; however, the organism was recovered on culture of their blood and kidneys. Microagglutinations conducted with the isolated organism showed it to be identical to the one involved in the laboratory accident, and convalescent titers of 1:400 to both his own strain and the standard laboratory strain of $L$. mini georgia left no doubt concerning the etiology of his disease.

\section{Comments}

This case demonstrates that it is possible to infect man and produce overt disease with $L$. mini georgia. The clinical picture closely resembled what is commonly called flu or la grippe, and if the history of a laboratory accident had not been documented the diagnosis might well have been missed. It is probable that this type of clinical picture with leptospirosis is much more common than is generally recognized.

The incubation period of 25 days was well defined and, when compared with the previously established incubation periods of 2 to 19 days (1), was inordinately long.

Although leucocytosis is the usual finding in Weil's disease, leucopenia has been reported in less severe leptospiral infections (2). Thus, the finding of leucopenia in this case is not unusual. Similarly, it has been noted frequently that cases of leptospirosis may have a recurrence of fever during the third week of illness (3).

The efficacy of antibiotic therapy in leptospirosis is undecided (4). Several authors feel 
that it exerts a favorable effect, particularly if given early in the course of disease (5-8). However, other studies seem to indicate that none of the commonly employed antibiotics are particularly effective in leptospirosis $(9$, 10), but because of the variability of severity of these infections any form of therapy is difficult to evaluate. In our patient, aureomycin in the dosage used failed to arrest the bacteremia, but we, of course, do not know if the therapy altered the course of the disease.

\section{Summary}

A laboratory infection with L. mini georgia, a new subserotype of the hebdomadis group, is reported. After an unusually long incubation period the disease was characterized by fever, frontal headache, and myalgia. Aureomycin therapy failed to eliminate the bacteremia. The similarity of mild leptospirosis to la grippe is noted.

\section{REFERENCES}

(1) Alston, J. M., and Broom, J. C. : Leptospirosis in man and animals. Edinburgh, E. \& S. Livingston, Ltd., 1958.
(2) Daniels, W. B., and Grennan, H. A.: Pretibial fever. J.A.M.A. 122 : 361-365 (1943).

(3) Gsell, O.: Leptospirosis. Bern, Huber, 1952.

(4) Kaltz, G.: The human leptospiroses. Am. J. Med. Sci. 233 : 320_333 (1957).

(5) MacKay-Dick, J., and Robinson, J. F.: Penicillin treatment of leptospirosis. Lancet 2: 346347 (1957).

(6) Patterson, H. M.: Weil's disease, observations in sixty-one cases with special reference to the use of penicillin in six cases. J.A.M.A. 134: 1077-1080 (1947).

(7) Symposium on the leptospiroses. Walter Reed Army Medical Center, Medical Science Pub. No. 1. Washington, D.C., 1952, pp. 211-219.

(8) Yoder, H. W., Bergman, E. N., and Gleiser, C. A. : Experimental canine leptospirosis. IV. Evaluation of selected antibiotics in the therapy of acute experimental icterohemorrhagiae infections in immature dogs. J. Infect. Dis. 100: 257-267 (1957).

(9) Hall, H. E., Hightower, J. A., Rivera, R. D., Byrne, R. J., Smadel, J. E., and Woodward, T. E. : Evaluation of antibiotic therapy in human leptospirosis. Ann. Int. Med. 35: 981988 (1951).

(10) Fairburn, A. C., and Semple, S. J. G.: Chloramphenicol and penicillin in the treatment of leptospirosis among troops in Malaya. Lancet 1: 13-16 (1956).

\section{New PHS Divisions in Reorganization}

The first major move in the Public Health Service reorganization recommended by a task force appointed by the Surgeon General establishes four new divisions in the Bureau of State Services.

The change, effective September 1, 1960, assigns all air pollution work to a Division of Air Pollution headed by Vernon G. MacKenzie, a career engineer officer active in air pollution control for the past 10 years. Dr. Richard A. Prindle, a physician who has been a specialist in health aspects of air pollution and chief of the Service's air pollution medical program for the last 2 years, is the deputy chief of the new division.

Occupational health activities are concentrated in a new Division of Occupational Health, with Dr. Harold J. Magnuson its chief. Dr. Magnuson has directed the Service's program in this field during the past 4 years. The action increases the potential for more funds and manpower for research on new chemicals and other industrial products and on development of safeguards for workers exposed to them. Such study contributes indirectly to protecting the public from new environmental health hazards.

A Division of Nursing, with Margaret Arnstein, a career nurse officer as chief, merges the former Division of Public Health Nursing and the Division of Nursing Resources. The new Division of Dental Public Health and Resources, headed by Dr. Donald J. Galagan, a career dental officer, combines the Division of Dental Public Health and the Division of Dental Resources. 